\title{
MOORA under Pythagorean Fuzzy Set for Multiple Criteria Decision Making
}

\author{
Luis Pérez-Domínguez $\mathbb{D}^{\mathbb{D}},{ }^{1}$ Luis Alberto Rodríguez-Picón $\mathbb{D}^{\mathrm{D}},{ }^{1}$ Alejandro Alvarado-Iniesta, ${ }^{1}$ \\ David Luviano Cruz $\left(\mathbb{D},{ }^{1}\right.$ and Zeshui $\mathrm{Xu}^{2}$ \\ ${ }^{1}$ Department of Industrial and Manufacturing Engineering, Universidad Autónoma de Ciudad Juárez, Ave. Del Charro 450 Norte, \\ 32315 Ciudad Juárez, CHIH, Mexico \\ ${ }^{2}$ Business School, Sichuan University, Chengdu, Sichuan 610064, China
}

Correspondence should be addressed to Luis Pérez-Domínguez; luis.dominguez@uacj.mx

Received 30 October 2017; Revised 12 February 2018; Accepted 12 March 2018; Published 23 April 2018

Academic Editor: Rosario Domingo

Copyright (C) 2018 Luis Pérez-Domínguez et al. This is an open access article distributed under the Creative Commons Attribution License, which permits unrestricted use, distribution, and reproduction in any medium, provided the original work is properly cited.

\begin{abstract}
The multiobjective optimization on the basis of ratio analysis (MOORA) method captures diverse features such as the criteria and alternatives of appraising a multiple criteria decision-making (MCDM) problem. At the same time, the multiple criteria problem includes a set of decision makers with diverse expertise and preferences. In fact, the literature lists numerous approaches to aid in this problematic task of choosing the best alternative. Nevertheless, in the MCDM field, there is a challenge regarding intangible information which is commonly involved in multiple criteria decision-making problem; hence, it is substantial in order to advance beyond the research related to this field. Thus, the objective of this paper is to present a fused method between multiobjective optimization on the basis of ratio analysis and Pythagorean fuzzy sets for the choice of an alternative. Besides, multiobjective optimization on the basis of ratio analysis is utilized to choose the best alternatives. Finally, two decision-making problems are applied to illustrate the feasibility and practicality of the proposed method.
\end{abstract}

\section{Introduction}

Recently, the area of multiple criteria decision making (MCDM) had suffered a rapid development. MCDM aims to provide methods of ranking alternatives or select the optimal alternatives among a set of possible alternatives regarding several criteria [1]. Due to the commonness of the MCDM problems in modern life, its theories have been widely applied in various domains like military affair, industrial engineering, macroeconomic domain, and management [2]. Likewise, there are numerous multicriteria methodologies to deliver aid in the problematic task of making this decision [3]. In this sense, the most commonly reported methodologies in the literature are elimination and choice translation reality (ELECTRE, 1968) [4], decision support system (DSS, 1971) [5], data envelopment analysis (DEA, 1978) [6], analytic hierarchy process (AHP, 1980) [7], technique for order of preference by similarity to ideal solution (TOPSIS, 1981) [8], dimensional analysis (DA, 1993) [9], multicriteria optimization and compromise solution (vlsekriterijumska optimizacija i kompromisno resenje, VIKOR, 1998) [10], analytic network process (ANP, 1996) [11], multiobjective optimization on the basis of ratio analysis (MOORA, 2006) [12], and preference selection index (PSI, 2010) [13]. In addition, there are conventional MCDM problems that only consider nonfuzzy (crisp) type for appraising the alternatives with respect to each criterion and preferences of the criteria. In this logic, the conventional MOORA method is proficient for establishing the evaluations and rankings of the alternatives without any complexity. Nonetheless, in real-world, there are MCDM problems, where the opinions (feeling, preferences) of the DMs for appraising the alternatives and criteria weights are commonly expressed by means of linguistic terms embracing ambiguity and hesitation $[14,15]$. In this manner, the classical MOORA method presents drawback for manipulating the nonfuzzy (crisp) and fuzzy (qualitative) information involved in a problem of MCDM $[16,17]$. Then, there exists the panorama to continue developing investigation in decision 
making to approaches to deal with incomplete and imprecise information involved in MCDM problems.

Moreover, there are frequently reported hybrid methods with fuzzy sets and equally fuzzy set theory has been generalized in order to manipulate vagueness [18]. Nevertheless, these methods by themselves in addition to the hybrids with fuzzy sets still have some drawbacks and there is an imperative demand to present new MCDM methods [3, 1921].

Additionally, current investigations assert that multicriteria methods are being combined with intuitionistic fuzzy sets (IFS). Principally, the IFS, introduced by Atanassov [22], become of a generality of the conventional fuzzy sets stated by Zadeh [23]. According to literature over the last decade, the academics have paid great attention to the use of IFS in MCDM [3, 24, 25]. The IFS are proficient at imprecise treatment and inexact data [26-28].

On the other hand, the Pythagorean fuzzy set (PFS) [2932] has arisen as an operational instrument for handling the vagueness of MCDM problems. The PFS is categorized by means of the affiliation degree and the nonaffiliation degree, whose sum of squares is less than or equal to 1 . In the circumstance, the PFS can explain the difficulties that the IFS cannot; for example, if a DM gives the membership degree and the nonmembership degree as 0.8 and 0.3 , respectively, then it is just operative for the PFS. In this sense, all the IFS degrees are a part of the PFS degrees, which specifies that the PFS is more proficient in handling problems of vagueness. Motivated by the advantages of the MOORA method and PF, this paper proposes two algorithms of MCDM by extending the MOORA to PF environments. Additionally, dealing with the last two challenges mentioned in the paragraph above arises. In this sense, the originality and contribution of this paper can be summarized as follows. First, we propose MOORA under PF environments to overcome the limitation of MOORA for dealing with any other type of arguments rather than crisp data and extend its potential applications to more extensive areas. Second, our approach can simultaneously handle quantitative (tangible) and qualitative (intangible) information, commonly presented in an MCDM problem. Hereafter, the intention of this paper is to extend the MOORA method under the PFS environment for the MCDM field.

The remainder of this paper is organized as follows. Section 2 briefly presents the concepts related to PFS. Section 3 presents the explanation of MOORA. Section 4 pronounces the method proposed in this work. In the Section 5 two numerical cases are presented to describe the proposed methodology and the conclusions are presented in Section 6

\section{Pythagorean Fuzzy Set}

Pythagorean fuzzy set (PFS) presented by [29, 33] is explained as follows.

Definition 1 (see [33]). Let $Y$ be an arbitrary nonempty set. A PFS $P$ is a mathematical object of the form

$$
P=\left\{\left\langle y, P\left(\mu_{A}(y), v_{A}(y)\right)\right\rangle \mid y \in Y\right\} .
$$

Thus, a Pythagorean fuzzy set $P$ in $Y=\{y\}$ is given by $P=\left\{\left\langle y, \mu_{P}(y), v_{P}(y)\right\rangle \mid y \in Y\right\}$.

Here $\mu_{P}(y)$ and $v_{P}(y): Y \rightarrow[0,1]$ depict the affiliation function and nonaffiliation function of the fuzzy set $A$; $\mu_{A}(y) \in[0,1]$ depict the affiliation of $y \in Y$ in $A$. At the same time, a PFS $A$ in $Y=\{y\}$ is defined as $A=\left\{\left\langle y, \mu_{A}(y), v_{A}(y)\right\rangle \mid\right.$ $y \in Y\}, \mu_{A}$ and $v_{A}: Y \rightarrow[0,1]$. With the condition $0 \leq \mu_{A}(y)+v_{A}(y) \leq 1, \forall y \in Y$, the numbers $\mu_{A}(y)$ and $v_{A}(y)$ depict the degree of affiliation and degree of nonaffiliation of element $y$ with respect $A$.

The number $\pi_{P}(y)$ is named the Pythagorean index degree of the hesitancy of $y$ in $P$ and can be stated as

$$
\pi_{P}(y)=\sqrt{1-\left(\mu_{P}^{2}(y)+v_{P}^{2}(y)\right)},
$$

where $\mu_{P}^{2}(y)+v_{P}^{2}(y) \leq 1$ for each $y \in Y$.

Hence, a PFS $P$ in $Y=\{y\}$ is fully defined with the form $P=\left\{\left\langle y, \mu_{P}(y), v_{P}(y), \pi_{P}(y)\right\rangle \mid y \in Y\right\}$. Here $\mu_{P}: Y \rightarrow[0,1]$; $v_{P}: X \rightarrow[0,1]$ and $\pi_{P}: X \rightarrow[0,1]$. Thus, diverse operations are presented over the PFSs [29]; some of them are revealed in (3), (4), and (5).

Definition 2 (see $[32,34]$ ). Assuming $\alpha_{1}=P\left\{\mu_{\alpha_{1}}, v_{\alpha_{1}}\right\}, \alpha_{2}=$ $P\left\{\mu_{\alpha_{2}}, v_{\alpha_{2}}\right\}$, and $\alpha=P\{\mu, v\}$ are three PFNs, then,

$$
\begin{aligned}
\alpha^{c} & =\left(v_{\alpha}, \mu_{\alpha}\right) \\
\alpha_{1} \oplus \alpha_{2} & =\left(\sqrt{\left(\mu_{A}+\mu_{B}-\mu_{A} \cdot \mu_{B}\right)},\left(v_{A} \cdot v_{A}\right)\right) ; \\
\alpha_{1} \otimes \alpha_{2} & =\left(\mu_{A} \cdot \mu_{B}, \sqrt{v_{A}+v_{A}-v_{A} \cdot v_{A}}\right) \\
n \alpha & =\left(\sqrt{1-\left(1-\mu_{\alpha}^{2}\right)^{n}},\left(v_{A}\right)^{n}\right), \quad n>0 .
\end{aligned}
$$

In fact, to rank the PFNs the next definition is presented.

Definition 3. Let $\alpha=P\left(\mu_{\alpha}, v_{\alpha}\right)$ describe a PFN; then the total function of $\theta(\alpha)$ is presented as

$$
\theta(\alpha)=\left(\mu_{\alpha}\right)^{2}-\left(v_{\alpha}\right)^{2}
$$

The large $\theta(\alpha)$ depict the best PFN.

Definition 4. Let $\alpha=P\left(\mu_{\alpha}, v_{\alpha}\right)$ represent a PFN; at that time the precision function of $\Omega(\alpha)$ is introduced as

$$
\Omega(\alpha)=\left(\mu_{\alpha}\right)^{2}+\left(v_{\alpha}\right)^{2} .
$$

Obviously, $\Omega(\alpha) \in[0,1]$. Thus, $0 \leq \Omega(\alpha)=\left(\mu_{\alpha}\right)^{2}+\left(v_{\alpha}\right)^{2} \leq$ 1. The superior rate of $\Omega(\alpha)$ describes the higher precision of the PFN $\alpha$.

Thus, per (2) and (8), $\pi_{\alpha}^{2}+\Omega(\alpha)=1$ can be determined. The inferior hesitant degree makes higher accuracy of the PFN $\alpha$.

Hence, with the total function and the precision function of PFNs, the ranking method for any two PFNs can be defined as follows.

Definition 5. Let $\alpha_{1}=P\left(\mu_{\alpha 1}, v_{\alpha 1}\right)$ and $\alpha_{2}=P\left(\mu_{\alpha 2}, v_{\alpha 2}\right)$ depict two PFNs. Here, $S\left(\alpha_{i}\right)(i=1,2)$ and $H\left(\alpha_{i}\right)(i=1,2)$ describe the rate and the precision of $\alpha_{1}$ and $\alpha_{2}$. Then, 
(i) if $S\left(\alpha_{1}\right)<S\left(\alpha_{2}\right)$, then $\alpha_{1}<\alpha_{2}$;

(ii) if $S\left(\alpha_{1}\right)=S\left(\alpha_{2}\right)$, then,

(1) if $H\left(\alpha_{1}\right)<H\left(\alpha_{2}\right)$, then $\alpha_{1}<\alpha_{2}$;

(2) if $H\left(\alpha_{1}\right)=H\left(\alpha_{2}\right)$, then $\alpha_{1}=\alpha_{2}$;

(3) if $H\left(\alpha_{1}\right)>H\left(\alpha_{2}\right)$, then $\alpha_{1}>\alpha_{2}$.

\section{MOORA}

The MOORA method was introduced by [12], which analyzes the complete throughput for each alternative as the variance between the sums of cost criteria and benefit criteria. Therefore, the MOORA method is definite through steps.

Step 1. Establish the decision-making matrix called $\beta$. In this manner $\beta$ collects $n$ rows that denote the alternatives $A^{1} \cdots A^{n}$ in assessment and $T+Z$ columns that characterize criteria in appraisal ( $T$ quantitative criteria and $Z$ qualitative criteria). In this mode, per (9), the decision-making matrix $\beta$ can be obtained as follows:

$$
\begin{aligned}
\beta= & {[V O, V S T] } \\
& A^{1} \\
& A^{2}\left[\begin{array}{cccccc}
x_{1}^{1} & \cdots & x_{T}^{1} & x_{T+1}^{1} & \cdots & x_{T+Z}^{1} \\
x_{1}^{2} & \cdots & x_{T}^{2} & x_{T+1}^{2} & \cdots & x_{T+1}^{2} \\
\cdot & \cdot & \cdot & \cdot & \cdot & \cdot \\
x_{1}^{n} & \cdots & x_{T}^{n} & x_{T+1}^{n} & \cdots & x_{T+Z}^{n}
\end{array}\right],
\end{aligned}
$$

where $A^{i}$ denote the alternatives, aimed at $k=1 \cdots n$, and $x_{l}^{k}$ reflect the inputs of the alternative $k$ with reference to criterion $l$.

Step 2. Proceed with the normalization of $\beta$ matrix. Here the Euclidean norm to the criterion $x_{l}$ is obtained by using

$$
\left|\beta_{l}\right|=\sqrt{\sum_{K=1}^{n} x_{l}^{2}} .
$$

Therefore, the normalization of each entry in the $\beta$ is calculated by using

$$
\bar{\beta} x_{k l}=\frac{x_{k l}}{\left|\beta_{l}\right|} .
$$

Step 3. Create the balanced normalized decision-making matrix called $\check{\xi}_{k l}$. Following [12] the different preferences of criteria, the evaluations $\check{\xi}_{k l}$ are computed by using

$$
\check{\xi}_{k l}=\omega_{i} \cdot N x_{k l} \text {. }
$$

Step 4. Analyze the global assessments of cost and benefit criteria for each $A_{i}$.

In this mode, the global evaluations of benefit criteria $N x_{i}$ are estimated as the sum of weights normalized per

$$
N x_{i}=\check{\xi}_{k l} \mid \in \delta^{\max },
$$

where $\delta^{\max }$ is related to $N x_{i}$.
TABLE 1: Scale for evaluation of the preferences of DMs and criteria.

\begin{tabular}{lc}
\hline Meaning & PFNs $(\mu, \nu)$ \\
\hline Apprentice (Ap)/Very Insignificant (VI) & $(0.10,0.90)$ \\
Learner (Lr)/Insignificant (I) & $(0.35,0.60)$ \\
Capable (Ct)/Average (A) & $(0.50,0.45)$ \\
Skillful (S)/Imperative (Im) & $(0.75,0.40)$ \\
Dominant (D)/Very Significative (VS) & $(0.90,0.10)$ \\
\hline
\end{tabular}

Likewise, the global assessments of cost criteria $N x_{j}$ are calculated by mean of

$$
N x_{j}=\check{\xi}_{k l} \mid \in \delta^{\mathrm{min}},
$$

where $\delta^{\mathrm{min}}$ is related to $N x_{j}$.

Step 5. Establish the contribution $N y_{i}$ value. $N y_{i}$ is obtained via (15) originated by [12].

$$
N y_{i}=\sum_{l=1}^{g} N x_{i}-\sum_{l=g+1}^{m} N x_{j},
$$

where $N y_{i}$ represents the contribution of each alternative $k=$ $1 \cdots n, i=1 \cdots g$ are the maximum criteria, and $l=g+1, g+$ $2, \ldots, m$ are the lowest criteria.

\section{MOORA under Pythagorean Fuzzy Environment (PF-MOORA)}

Let $A=\left\{A_{1}, A_{2}, \ldots, A_{i}, \ldots, A_{n}\right\}$ represent a set of alternatives and $x=\left\{x_{1}, x_{2}, \ldots, x_{j}, \ldots, x_{m}\right\}$ depict a collection of criteria to be appraised. The PF-MOORA method is described in the following steps.

Step 1. Establish a team of DMs and capture the preferences of each one. Here $\mathrm{DM}=\left\{\mathrm{DM}_{1}, \mathrm{DM}_{2}, \ldots, \mathrm{DM}_{k}, \ldots, \mathrm{DM}_{l}\right\}$ denote a group of decision makers (DMs). The preferences of each DM are evaluated via a linguistic term mapping by PFN. The scale and their corresponding PFN used are shown in Table 1.

Let $\mathrm{DM}_{k}=\left\{\mu_{k}, v_{k}, \pi_{k}\right\}$ be a Pythagorean fuzzy number for evaluation of DM. Then, the equivalent weight of DM is calculated using the concept fuzzy weighted arithmetic Pythagorean represented by

$$
\varepsilon_{k}=\frac{\left(\mu_{k}+\pi_{k}\left(\mu_{k} /\left(\mu_{k}+v_{k}\right)\right)\right)}{\sum_{k=1}^{l}\left(\mu_{k}+\pi_{k}\left(\mu_{k} /\left(\mu_{k}+\nu_{k}\right)\right)\right)},
$$

where $\sum_{k=1}^{l} \varepsilon_{k}=1$.

Step 2. State the preferences of criteria. Hence, all opinions/preferences need to be considered and fused into one.

Thus, in order to appraise the preference criteria by every DM, the scale linguistic from Table 1 can be used. 
TABLE 2: Scale for assessment alternatives.

\begin{tabular}{lc}
\hline Meaning & PFNs $(\mu, \nu)$ \\
\hline Enormously Bad (EB)/Extremely Low (EL) & $\{0.10,0.99\}$ \\
Tall Bad (TB)/Very Little (VL) & $\{0.10,0.97\}$ \\
Not Good (NG)/Little (L) & $\{0.25,0.92\}$ \\
Middle Bad (MB)/Middle Little (ML) & $\{0.40,0.87\}$ \\
Fair-middle (F)/Middle (M) & $\{0.50,0.80\}$ \\
Middle Good (MG)/Middle High (MH) & $\{0.6,0.71\}$ \\
Tall (T)/Big (B) & $\{0.70,0.60\}$ \\
Very Big (VB)/Very Tall (VT) & $\{0.8,0.44\}$ \\
Exceptional (E)/Tremendously High (TH) & $\{1,0\}$ \\
\hline
\end{tabular}

Let $\omega_{j}^{(k)}=\left\{\mu_{j}^{(k)}, v_{j}^{(k)}\right\}$ be a PFN given to criterion $x_{l}$ by the DM. Then, the weights of the criteria are computed by means of the IPFWA operator proposed by [32]

$$
\begin{aligned}
\omega_{j} & =\operatorname{PFWA}\left(\omega_{j}^{(1)}, \omega_{j}^{(2)}, \ldots, \omega_{j}^{(k)}, \ldots, \omega_{j}^{(l)}\right) \\
& =\lambda_{1} \omega_{j}^{(1)} \oplus \lambda_{2} \omega_{j}^{(2)} \oplus \cdots \oplus \lambda_{k} \omega_{j}^{(k)} \oplus \cdots \oplus \lambda_{l} \omega_{j}^{(l)} \\
& =P\left[\sum_{j=1}^{n} \lambda_{j} \mu_{j}, \sum_{j=1}^{n} \lambda_{j} \nu_{j}\right]
\end{aligned}
$$

where $\omega_{j}=\left\{\mu_{j}, \nu_{j}\right\}$ and $\omega_{j}=\left\{\omega_{1}, \omega_{2}, \ldots, \omega_{j}, \ldots, \omega_{m}\right\}$ and $\sum_{j=1}^{m} \omega_{j}=1$.

Step 3. Create the combined Pythagorean fuzzy decision matrix denoting the assessment of $A_{i}$ according to the preferences of the DMs.

Let $R^{(k)}=\left(x_{i j}^{(k)}\right)_{n x m}$ be a Pythagorean fuzzy decision matrix (PFDM) of each DM. The scale used to appraise each alternative is presented in Table 2.
All preferences of the DMs need to be involved into a gathered Pythagorean fuzzy decision matrix (PFDM) through PFWA operator: $R=\left(x_{i j}\right)_{n \times m}$.

$$
\begin{aligned}
x_{k l} & =\operatorname{PFWA}\left(x_{k l}^{(1)}, x_{k l}^{(2)}, \ldots, x_{k l}^{(t)}, \ldots, x_{k l}^{(z)}\right) \\
& =\omega_{1} x_{k l}^{(1)} \oplus \omega_{2} x_{k l}^{(2)} \oplus \cdots \oplus \omega_{z} x_{k l}^{(z)} \oplus \cdots \oplus \omega_{j} x_{k l}^{(t)} \\
& =\left[\sum_{k=1}^{l}\left(\left(\omega \cdot \mu_{k l}^{(z)}\right),\left(\omega \cdot v_{k l}^{(z)}\right)\right)\right]
\end{aligned}
$$

where $x_{i j}=\left\{\mu_{A_{k}\left(X_{l}\right)}, v_{A_{k}\left(X_{l}\right)}, \pi_{A_{k}\left(X_{l}\right)}\right\}(k=1,2, \ldots, n ; l=$ $1,2, \ldots, m)$

Then, the PFDM is defined as

Explicitly,

$$
\operatorname{PFDM}=R=\left[\begin{array}{ccc}
x_{11} & \cdots & x_{1 m} \\
\vdots & \ddots & \vdots \\
x_{n 1} & \cdots & x_{n m}
\end{array}\right] .
$$

$R$

$$
=\left[\begin{array}{ccc}
\left\{\mu_{A_{1}\left(X_{1}\right)}, v_{A_{1}\left(X_{1}\right)}, \pi_{A_{1}\left(X_{1}\right)}\right\} & \cdots & \left\{\mu_{A_{1}\left(X_{m}\right)}, v_{A_{1}\left(X_{m}\right)}, \pi_{A_{1}\left(X_{m}\right)}\right\} \\
\vdots & \ddots & \vdots \\
\left\{\mu_{A_{n}\left(X_{1}\right)}, v_{A_{n}\left(X_{1}\right)}, \pi_{A_{n}\left(X_{1}\right)}\right\} & \cdots & \left\{\mu_{A_{n}\left(X_{m}\right)}, v_{A_{n}\left(X_{m}\right)}, \pi_{A_{n}\left(X_{m}\right)}\right\}
\end{array}\right] .
$$

Step 4. Calculate the combined weighted Pythagorean fuzzy decision matrix called $R^{\prime}$. In this step, $R^{\prime}$ is computed by means of APFDM and the vector $\omega_{j}$. The elements of $R^{\prime}$ are calculated via

$$
\begin{array}{r}
\text { WPFDM }=R^{\prime}=R \cdot \omega=\left\{\left\langle x, \mu_{A_{i}}(x) \cdot \mu_{\omega}(x), v_{A_{i}}(x)+v_{\omega}(x)-v_{A_{i}}(x) \cdot v_{\omega}(x)\right\rangle \mid x \in X\right\} \\
R^{\prime}=\left[\begin{array}{ccc}
\left\{\mu_{A_{1}^{\prime}\left(X_{1}\right)}, v_{A_{1}^{\prime}\left(X_{1}\right)}, \pi_{A_{1}^{\prime}\left(X_{1}\right)}\right\} & \cdots & \left\{\mu_{A_{1}^{\prime}\left(X_{m}\right)}, v_{A_{1}^{\prime}\left(X_{m}\right)}, \pi_{A_{1}^{\prime}\left(X_{m}\right)}\right\} \\
\vdots & \ddots & \vdots \\
\left\{\mu_{A_{n}^{\prime}\left(X_{1}\right)}, v_{A_{n}^{\prime}\left(X_{1}\right)}, \pi_{A_{n}^{\prime}\left(X_{1}\right)}\right\} & \cdots & \left\{\mu_{A_{n}^{\prime}\left(X_{m}\right)}, v_{A_{n}^{\prime}\left(X_{m}\right)}, \pi_{A_{n}^{\prime}\left(X_{m}\right)}\right\}
\end{array}\right] .
\end{array}
$$

Step 5. Compute the sum of $B N x_{i}$ and $C x_{j}$.

Consequently, (23) denotes the sum of benefit criteria:

$$
B N x_{i}=\sum_{i=1}^{g}\left(\mu_{A_{i}^{\prime}}\left(x_{i}\right), v_{A_{i}^{\prime}}\left(x_{i}\right), \pi_{A_{i}^{\prime}}\left(x_{i}\right)\right),
$$

where $B N x_{i}$ describe the benefit criteria for the alternative $k=1 \cdots n \cdot x_{l}=1 \cdots g$ denote the maximum criteria. Then, (24) defines the sum of the cost criteria.

$$
C x_{j}=\sum_{j=g+1}^{m}\left(\mu_{A_{i}^{\prime}}\left(x_{j}\right), v_{A_{i}^{\prime}}\left(x_{j}\right), \pi_{A_{i}^{\prime}}\left(x_{j}\right)\right) \text {, }
$$

where $C x_{j}$ denotes the sum of the cost criteria for alternative $k=1 \cdots n$, and $x_{l}=g+1, g+2, \ldots, m$ are minimum criteria.

Step 6. Defuzzify $B N x$ and $C x_{j}$ by mean of

$$
\begin{aligned}
& N x_{i}=\left(\mu_{\alpha_{x_{i}}}\right)^{2}-\left(v_{\alpha_{x_{i}}}\right)^{2} \\
& N x_{j}=\left(\mu_{\alpha_{x_{j}}}\right)^{2}-\left(v_{\alpha_{x_{j}}}\right)^{2} .
\end{aligned}
$$

Step 7. Calculate the value of $N y_{i}$.

It is obtained by means of

$$
N y_{i}=N x_{i}-N x_{j}
$$




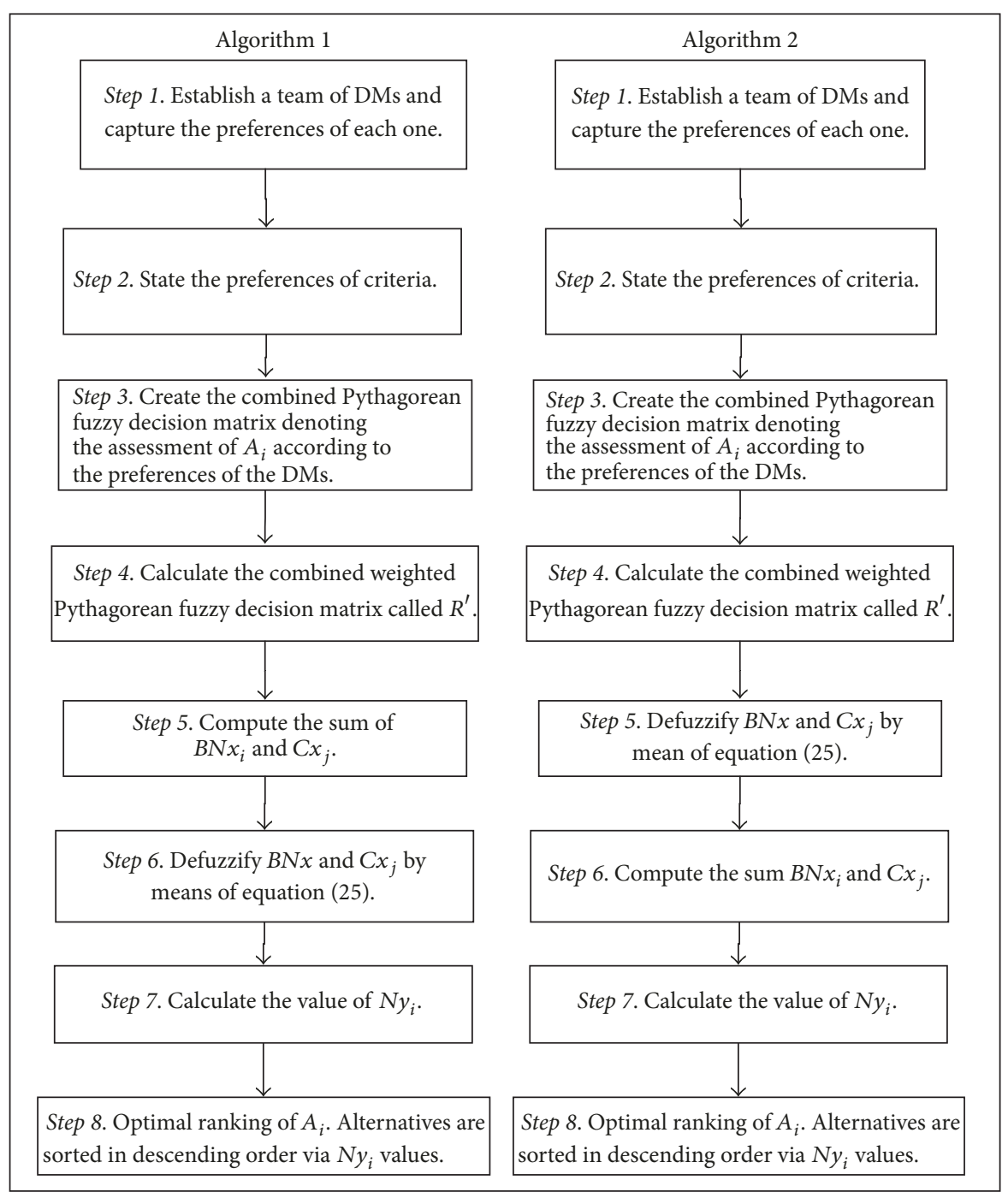

FIGURE 1: Flowcharts of the algorithms of the PF-MOORA method.

Step 8. Optimal ranking of $A_{i}$ : alternatives are sorted in descending order via $N y_{i}$ values.

In order to explain the proposed method, Figure 1 shows the flowcharts of the different steps used by the PF-MOORA method.

Here, Algorithm 1 is capable of working under completely fuzzy information. Likewise, Algorithm 2 is proficient to work with hybrid information, handling nonfuzzy and fuzzy data, since MCDM problems simultaneously may include both quantitative (nonfuzzy) and qualitative (fuzzy) data.

\section{Numerical Case}

Example 1 (Algorithm 1). This case belongs to an organization from Maquiladoras of Juárez, México. In fact, the organization is an assembly manufacturing company, in which several components are assembled in its production line. A cost reduction project was implemented and opportunity area belongs to packing item. This company proposes appraising five packing suppliers of electronic components. In this sense, two decision makers are invited for the assessment. In addition, four criteria are raised for depiction of the substantial features of the providers. In this manner, the criteria involved are described as follows:

(i) Cost $\left(x_{1}\right)$ : minimum values are ideal.

(ii) Service $\left(x_{2}\right)$ : great assessments are preferred.

(iii) Lead time $\left(x_{3}\right)$ : high appraisals are preferred.

(iv) Quality $\left(x_{4}\right)$ : great appraisals are preferred.

Thus, the collection of suppliers is designated by $P=$ $\left\{P_{1}, P_{2}, P_{3}, P_{4}, P_{5}\right\}$.

The procedure followed to select the best supplier is shown below.

Step 1. Establish a team of DMs and capture the preferences of each one. 


$$
\varepsilon_{1,2}=\frac{(0.75+0.53(0.75 /(0.75+0.4)))}{(0.75+0.53(0.75 /(0.75+0.4)))+(0.75+0.53(0.75 /(0.75+0.4)))}=0.5
$$

The DM preferences are presented in Table 3. Hence, the weight of each DM is obtained by means of (16).

Step 2. State the preferences of the criteria.

The appraisal of each DM is represented in Table 4. The preferences of the DMs are unified via (17).

$$
\omega_{\left\{x_{1}, x_{2}, x_{3}, x_{4}\right\}}=\left[\begin{array}{l}
\{0.24\} \\
\{0.24\} \\
\{0.22\} \\
\{0.31\}
\end{array}\right]^{T} .
$$

Step 3. Create the combined Pythagorean fuzzy decision matrix denoting the assessment of $A_{i}$ by the preferences of the DMs.

The evaluations given for each DM are specified in Table 5. The PFDM is given by (18) and the results are as follows:

$$
R=\left[\begin{array}{lllll}
\{0.10,0.97,0.22\} & \{0.25,0.90,0.36\} & \{1.00,0.00,0.00\} & \{0.80,0.44,0.41\} \\
\{0.40,0.87,0.29\} & \{0.60,0.71,0.37\} & \{0.50,0.80,0.33\} & \{0.70,0.60,0.39\} \\
\{0.96,0.04,0.28\} & \{0.96,0.04,0.28\} & \{0.96,0.04,0.28\} & \{0.10,0.97,0.22\} \\
\{0.71,0.50,0.50\} & \{0.10,0.97,0.22\} & \{0.10,0.97,0.22\} & \{0.25,0.92,0.30\} \\
\{0.50,0.80,0.33\} & \{0.40,0.87,0.29\} & \{0.71,0.50,0.50\} & \{0.50,0.80,0.33\}
\end{array}\right] .
$$

Step 4. Calculate the combined weighted Pythagorean fuzzy decision matrix called $R^{\prime}$.

$$
\begin{aligned}
& \text { The elements of } R^{\prime} \text { are calculated via }(21) . \\
& R^{\prime} \\
& =\left[\begin{array}{llll}
\{0.1,0.8,0.1\} & \{0.2,0.8,0.1\} & \{0.4,0.6,0.1\} & \{0.2,0.7,0.0\} \\
\{0.3,0.6,0.1\} & \{0.5,0.4,0.1\} & \{0.1,0.8,0.1\} & \{0.2,0.8,0.1\} \\
\{0.5,0.4,0.1\} & \{0.6,0.3,0.1\} & \{0.3,0.7,0.1\} & \{0.0,0.9,0.0\} \\
\{0.4,0.5,0.1\} & \{0.1,0.8,0.1\} & \{0.0,0.9,0.0\} & \{0.1,0.9,0.0\} \\
\{0.3,0.6,0.1\} & \{0.3,0.6,0.1\} & \{0.2,0.8,0.1\} & \{0.1,0.9,0.0\}
\end{array}\right] .
\end{aligned}
$$$$
R^{\prime}
$$

Step 5. Compute the sum of $B N x_{i}$ and $C x_{j}$.

Table 6 shows the results of $B N x_{i}$ values calculated via (23).

Table 7 describes the $C x_{j}$ values calculated using (24).

Step 6. Defuzzify $B N x$ and $C x_{j}$ by means of (25).

Tables 8 and 9 describe the results.

Step 7. Calculate the value of $N y_{i}$.

Table 10 shows the ratio for each alternative and its ranking.

Step 8. Rank the alternatives.

The results reveal $P_{1}>P_{2}>P_{3}>P_{5}>P_{4}$. Then, alternative $P_{1}$ is selected as the top supplier.
Example 2 (Algorithm 2). In fact, this case belongs to a reallife problem; there is a manufacturing company that is in charge of manufacturing fixtures, work tables, and holders. The most commonly used materials are plastic, aluminum, and steel. The machines used in CNC are milling machines, lathe, and grinding machines. The current tool selection is based on expertise from operators. Consequently, there is problem reflected in the quality metric from customers due to the poor quality of parts (products). Then, after a sixsigma project and root cause analyses were identified, the major cause is related to the wrong tools assigned to the manufacturing process. In this manner, the MCDM problem is associated with selecting the tools indicated with their respective machining criteria for the types of material used in the manufacturing process through a CNC milling machine.

In this sense, four DMs were invited to the assessment process. Likewise, a group of five tools are involved which can be called alternatives $T=\left(T_{1}, T_{2}, T_{3}, T_{4}, T_{5}\right)$. At the same time, six criteria are considered and are described as follows:

(i) RPM $\left(c_{1}\right)$ : this describes the revolutions per minute $(\mathrm{rpm})$ from the spindle of the lathe. High values are ideal (crisp/nonfuzzy criterion).

(ii) Advance on $X / Y\left(c_{2}\right)$ : it describes the advance on axes of $X$ and $Y$ depicted in in/min, respectively. Great assessments are preferred (crisp/nonfuzzy criterion).

(iii) Advance on $Z\left(c_{3}\right)$ : it describes the advance on axes of $Z$ depicted in in/min. High appraisals are preferred (crisp/nonfuzzy criterion). 
TABLE 3: The importance of DM.

\begin{tabular}{lcc}
\hline Decision maker & 1 & 2 \\
\hline Linguistic term & $\mathrm{D}$ & $\mathrm{D}$ \\
PF number & $\{0.75,0.4,0.53\}$ & $\{0.75,0.4,0.53\}$ \\
Weight & 0.5 & 0.5 \\
\hline
\end{tabular}

TABLE 4: The importance of criteria.

\begin{tabular}{lcccc}
\hline $\mathrm{DMs}$ & $x_{1}$ & $x_{2}$ & $x_{3}$ & $x_{4}$ \\
\hline $\mathrm{DM}_{1}$ & $\mathrm{Im}$ & $\mathrm{A}$ & $\mathrm{Lr}$ & $\mathrm{VI}$ \\
$\mathrm{DM}_{2}$ & $\mathrm{~A}$ & $\mathrm{Im}$ & $\mathrm{VI}$ & $\mathrm{Lr}$ \\
\hline
\end{tabular}

TABLE 5: The assessments of alternatives $A_{i}$.

\begin{tabular}{cccccc}
\hline DMs & Supplier & \multicolumn{4}{c}{ Criteria } \\
\hline \multirow{5}{*}{ DM1 } & & $X_{1}$ & $X_{2}$ & $X_{3}$ & $X_{4}$ \\
& $P_{1}$ & $\mathrm{VL}$ & $\mathrm{L}$ & $\mathrm{E}$ & $\mathrm{VT}$ \\
& $P_{2}$ & $\mathrm{ML}$ & $\mathrm{T}$ & $\mathrm{F}$ & $\mathrm{T}$ \\
& $P_{3}$ & $\mathrm{VB}$ & $\mathrm{VB}$ & $\mathrm{VB}$ & $\mathrm{TB}$ \\
& $P_{4}$ & $\mathrm{MH}$ & $\mathrm{TB}$ & $\mathrm{TB}$ & $\mathrm{L}$ \\
& $P_{5}$ & $\mathrm{M}$ & $\mathrm{MB}$ & $\mathrm{MG}$ & $\mathrm{F}$ \\
\hline \multirow{5}{*}{$\mathrm{DM} 2$} & $P_{1}$ & $\mathrm{~L}$ & $\mathrm{MB}$ & $\mathrm{E}$ & $\mathrm{TH}$ \\
& $P_{2}$ & $\mathrm{M}$ & $\mathrm{VB}$ & $\mathrm{L}$ & $\mathrm{VB}$ \\
& $P_{3}$ & $\mathrm{~B}$ & $\mathrm{TH}$ & $\mathrm{B}$ & $\mathrm{L}$ \\
& $P_{4}$ & $\mathrm{MH}$ & $\mathrm{L}$ & $\mathrm{EB}$ & $\mathrm{MB}$ \\
& $P_{5}$ & $\mathrm{~L}$ & $\mathrm{~F}$ & $\mathrm{MB}$ & $\mathrm{MB}$ \\
\hline
\end{tabular}

TABLE 6: $B N x_{i}$ values.

\begin{tabular}{lccc}
\hline Alternatives & $\mu$ & $\nu$ & $\pi$ \\
\hline$P_{1}$ & 0.609 & 0.301 & 0.09 \\
$P_{2}$ & 0.636 & 0.245 & 0.119 \\
$P_{3}$ & 0.751 & 0.18 & 0.069 \\
$P_{4}$ & 0.212 & 0.629 & 0.159 \\
$P_{5}$ & 0.481 & 0.395 & 0.125 \\
\hline
\end{tabular}

TABLE 7: $C x_{j}$ values.

\begin{tabular}{lccc}
\hline Supplier & $\mu$ & $\nu$ & $\pi$ \\
\hline$P_{1}$ & 0.115 & 0.77 & 0.115 \\
$P_{2}$ & 0.292 & 0.613 & 0.095 \\
$P_{3}$ & 0.488 & 0.399 & 0.113 \\
$P_{4}$ & 0.388 & 0.51 & 0.102 \\
$P_{5}$ & 0.251 & 0.643 & 0.106 \\
\hline
\end{tabular}

(iv) Cutting speed $\left(c_{4}\right)$ : it describes the cutting speed depicted in $\mathrm{ft} /$ minute. Great appraisals are preferred. Minimum evaluations are desired (crisp/nonfuzzy criterion).

(v) Machining finish $\left(c_{5}\right)$ : it is associated with the machining finish of the work piece. Great values are ideal (subjective/fuzzy criterion).
TABLE 8: Defuzzification of benefits $N x_{i}$.

\begin{tabular}{lc}
\hline Alternatives & Crisp \\
\hline$P_{1}$ & 0.641 \\
$P_{2}$ & 0.675 \\
$P_{3}$ & 0.767 \\
$P_{4}$ & 0.32 \\
$P_{5}$ & 0.538 \\
\hline
\end{tabular}

TABle 9: Defuzzification of costs $N x_{j}$.

\begin{tabular}{lc}
\hline Alternatives & Crisp \\
\hline$P_{1}$ & 0.207 \\
$P_{2}$ & 0.354 \\
$P_{3}$ & 0.54 \\
$P_{4}$ & 0.445 \\
$P_{5}$ & 0.323 \\
\hline
\end{tabular}

TABLE 10: Rank for each alternative.

\begin{tabular}{lcc}
\hline Alternatives & PF-MOORA method proposed & Rank \\
\hline$P_{1}$ & 0.576 & 1 \\
$P_{2}$ & 0.415 & 2 \\
$P_{3}$ & 0.337 & 3 \\
$P_{4}$ & -0.049 & 5 \\
$P_{5}$ & 0.294 & 4 \\
\hline
\end{tabular}

(vi) Geometry of the parts $\left(c_{6}\right)$ : it is related to how complex the shapes of manufacturing of the parts are. High evaluation are desired (subjective/fuzzy criterion).

Step 1. Establish a team of DMs and capture the preferences of each one.

Table 11 describes the results.

Step 2. State the preferences of the criteria.

Table 12 illustrate the results.

$$
\omega_{\left\{x_{1}, x_{2}, x_{3}, x_{4}\right\}}=\left[\begin{array}{l}
\{0.06\} \\
\{0.19\} \\
\{0.26\} \\
\{0.35\} \\
\{0.03\} \\
\{0.10\}
\end{array}\right]^{T} .
$$

Step 3. Create the combined Pythagorean fuzzy decision matrix denoting the assessment of $A_{i}$ according to the preferences of the DMs. 
TABLE 11: Comparison of rank for each alternative.

\begin{tabular}{lcccc}
\hline Decision maker & 1 & 2 & 3 & 4 \\
\hline Linguistic term & $\mathrm{Ct}$ & $\mathrm{Lr}$ & $\mathrm{D}$ & $\mathrm{D}$ \\
PF number & $\{0.50,0.45,0.74\}$ & $\{0.35,0.45,0.82\}$ & $\{0.90,0.10,0.42\}$ & $\{0.75,0.4,0.53\}$ \\
Weight & 0.22 & 18 & 0.32 & 0.28 \\
\hline
\end{tabular}

TABLE 12: Comparison of rank for each alternative.

\begin{tabular}{lcccccc}
\hline $\mathrm{DMs}$ & $x_{1}$ & $x_{2}$ & $x_{3}$ & $x_{4}$ & $x_{5}$ & $x_{6}$ \\
\hline $\mathrm{DM}_{1}$ & $\mathrm{VS}$ & $\mathrm{I}$ & $\mathrm{A}$ & $\mathrm{VI}$ & $\mathrm{I}$ & $\mathrm{Im}$ \\
$\mathrm{DM}_{2}$ & $\mathrm{~S}$ & VI & $\mathrm{I}$ & $\mathrm{I}$ & $\mathrm{VS}$ & $\mathrm{Im}$ \\
$\mathrm{DM}_{3}$ & $\mathrm{~A}$ & $\mathrm{D}$ & $\mathrm{Im}$ & $\mathrm{A}$ & $\mathrm{A}$ & $\mathrm{A}$ \\
$\mathrm{DM}_{4}$ & $\mathrm{VS}$ & $\mathrm{Im}$ & $\mathrm{VI}$ & $\mathrm{Im}$ & $\mathrm{A}$ & $\mathrm{VI}$ \\
\hline
\end{tabular}

Our MCDM problem involves crisp and fuzzy criteria. The crisp matrix is called $T$ and depicted as

$$
T=\left[\begin{array}{llll}
5000 & 50 & 5 & 0.050 \\
5000 & 50 & 5 & 0.025 \\
3500 & 30 & 5 & 0.020 \\
3000 & 30 & 3 & 0.015 \\
4000 & 10 & 2 & 0.007 \\
4000 & 5 & 2 & 0.011
\end{array}\right]
$$

and $\ddot{Y}$ is called Pythagorean matrix depicting the fuzzy criteria:

$$
\ddot{Y}=\left[\begin{array}{ll}
(0.33,0.70) & (0.09,0.98) \\
(0.19,0.75) & (0.19,0.91) \\
(0.30,0.55) & (0.30,0.68) \\
(0.26,0.60) & (0.26,0.87) \\
(0.12,0.90) & (0.12,0.96) \\
(0.45,0.60) & (0.45,0.73)
\end{array}\right]
$$

Finally, the combined Pythagorean decision matrix is called $\xi$ :

$$
\xi\left[\begin{array}{llllll}
0.49 & 0.60 & 0.52 & 0.81 & (0.33,0.70) & (0.09,0.98) \\
0.49 & 0.60 & 0.52 & 0.41 & (0.19,0.75) & (0.19,0.91) \\
0.34 & 0.36 & 0.52 & 0.32 & (0.30,0.55) & (0.30,0.68) \\
0.30 & 0.36 & 0.31 & 0.24 & (0.26,0.60) & (0.26,0.87) \\
0.39 & 0.12 & 0.21 & 0.08 & (0.12,0.90) & (0.12,0.96) \\
0.39 & 0.06 & 0.21 & 0.08 & (0.45,0.60) & (0.45,0.73)
\end{array}\right] .
$$

TABLE 13: Defuzzy values of $B N x$ and $C x_{j}$.

\begin{tabular}{lcc}
\hline Alternatives & $B N x$ & $C x_{j}$ \\
\hline$T_{1}$ & -0.830 & -0.996 \\
$T_{2}$ & -0.871 & -0.978 \\
$T_{3}$ & -0.747 & -0.917 \\
$T_{4}$ & -0.781 & -0.964 \\
$T_{5}$ & -0.952 & -0.991 \\
$T_{6}$ & -0.753 & -0.917 \\
\hline
\end{tabular}

TABLE 14: $B N x$ and $C x_{j}$ values.

\begin{tabular}{lcc}
\hline Alternatives & $B N x$ & $C x_{j}$ \\
\hline$T_{1}$ & -0.517 & -0.746 \\
$T_{2}$ & -0.699 & -0.728 \\
$T_{3}$ & -0.613 & -0.713 \\
$T_{4}$ & -0.678 & -0.815 \\
$T_{5}$ & -0.900 & -0.914 \\
$T_{6}$ & -0.701 & -0.851 \\
\hline
\end{tabular}

Step 4. Calculate the combined weighted Pythagorean fuzzy decision matrix (WPFDM).

$$
\begin{aligned}
& R^{\prime} \\
& =\left[\begin{array}{cccccc}
0.03 & 0.11 & 0.14 & 0.28 & (0.16,0.03) & (0.03,1.01) \\
0.03 & 0.11 & 0.14 & 0.14 & (0.09,0.94) & (0.06,0.99) \\
0.02 & 0.07 & 0.14 & 0.11 & (0.14,0.88) & (0.10,0.96) \\
0.02 & 0.07 & 0.08 & 0.09 & (0.13,0.89) & (0.08,0.99) \\
0.02 & 0.02 & 0.05 & 0.03 & (0.06,0.98) & (0.04,1.0) \\
0.02 & 0.01 & 0.05 & 0.03 & (0.22,0.89) & (0.15,0.97)
\end{array}\right] .
\end{aligned}
$$

Step 5. Defuzzify $B N x_{i}$ and $C x_{j}$ by means of (25).

Table 13 depicts the fuzzification related to $B N x_{i}$ and $C x_{j}$ criteria.

Step 6. Compute the sum of $B N x_{i}$ and $C x_{j}$.

Table 14 denotes the results.

Step 7. Calculate the value of $N y_{i}$.

Table 15 depicts the results.

Step 8. Rank the alternatives. 
TABLE 15: Rank for each alternative via PF-MOORA.

\begin{tabular}{lcc}
\hline Alternative & $N y_{i}$ & Rank \\
\hline$T_{1}$ & 0.229 & 1 \\
$T_{2}$ & 0.028 & 5 \\
$T_{3}$ & 0.100 & 4 \\
$T_{4}$ & 0.137 & 3 \\
$T_{5}$ & 0.014 & 6 \\
$T_{6}$ & 0.151 & 2 \\
\hline
\end{tabular}

TABLE 16: Comparison of rank for each alternative.

\begin{tabular}{lcccc}
\hline Alternatives & IF-MOORA & PF-TOPSIS & $\begin{array}{c}\text { PF-MOORA } \\
\text { method } \\
\text { proposed }\end{array}$ & Rank \\
\hline$P_{1}$ & 0.434 & -0.219 & 0.576 & 1 \\
$P_{2}$ & 0.321 & -1.135 & 0.415 & 2 \\
$P_{3}$ & 0.227 & -1.005 & 0.337 & 3 \\
$P_{4}$ & -0.124 & -0.124 & -0.049 & 5 \\
$P_{5}$ & 0.215 & -0.760 & 0.294 & 4 \\
\hline
\end{tabular}

TABLE 17: Comparison of rank for each alternative.

\begin{tabular}{ll}
\hline PF-TOPSIS & $T_{1}>T_{5}>T_{2}>T_{3}>T_{6}>T_{4}$ \\
\hline PF-MOORA proposed & $T_{1}>T_{5}>T_{4}>T_{3}>T_{6}>T_{2}$ \\
PF-TODIM & $T_{3}>T_{5}>T_{6}>T_{4}>T_{2}>T_{1}$ \\
\hline
\end{tabular}

Table 14 shows the results in which the order of the alternatives reveals that tool number 5 is the best option.

$$
T_{5}>T_{2}>T_{1}>T_{4}>T_{3}>T_{6} .
$$

After trials run implemented using $T_{5}$, good improvements are seen with regard to the quality of the products manufactured by the company involved in this study.

5.1. Comparison with Other Methods. In this section, we evaluate the method proposed through comparison with alternative methods. To validate the effectiveness of both PFMOORA, we conducted a comparative analysis with respect to the Pythagorean fuzzy TOPSIS (PF-TOPSIS) and the intuitionistic fuzzy MOORA (IF-MOORA)

The results reveal $P_{1}>P_{2}>P_{3}>P_{5}>P_{4}$ as seen in Table 16. Likewise, the results are just as our method proposed. At the same time, an advantage of PF-MOORA is shown in comparison to alternative methods with regard to contribution value about the ranking of the best alternative. It is clear that the PF-MOORA method is more proficient due to the Pythagorean fuzzy taking into count the membership and the nonmembership degrees to be operative and capture the uncertainty in MCDM problems.

Likewise, a second comparison was performed in Example 2. Table 17 illustrates the results.

The results of comparisons between PF-TOPSIS and our proposed method show coincidence in the selection and determine $T_{1}$ to be the best alternative. However, the PFTODIM reports different order in alternatives as shown in Table 17. In general, the methods of MCDM present a drawback with regard to how to operate nonfuzzy and fuzzy data simultaneously. Similarly, there is weakness in the manipulation of the imprecision and uncertainty involved in measuring the preferences of the decision makers when evaluating criteria and alternatives [35-37]. In this sense, the PF-MOORA method introduces two algorithms in order to manipulate fuzzy and nonfuzzy data. In this mode our method describes a systematic way and computational ratio to choose the best alternative. At the same time, PF-MOORA requires low setup time to carry out the analysis for determining the best alternative.

\section{Conclusions}

This study introduces a hybrid of MOORA and Pythagorean fuzzy sets (PF-MOORA) for multiple criteria decision making. The PF-MOORA method is defined via eight steps, and two experiments were carried out to illustrate it. The proposed methodology delivers a strong hybrid method that can give decision makers support for choosing the best alternative. In addition to the advantage of this study, intangible information that carries flexibility to handling this kind of data involved in MCDM problems is addressed. At the same time, the comparisons reveal the potential of PFMOORA to assign the ranking of the best alternative and coincidences with the results from PF-TOPSIS.

In future work, it would be motivating to apply PFMOORA to diverse MCDM problems, for example, robot selection, risk management, personnel selection, and project selection. Lastly, making comparisons with other methods and appraising the results are recommended, while, at the same time, exploring diverse aggregation operators to evaluate it.

\section{Conflicts of Interest}

The authors state that there are no conflicts of interest concerning the publication of this paper.

\section{Acknowledgments}

The authors appreciate the funding given by the Mexican Secretariat of Public Education no. 511-6/17-7605.

\section{References}

[1] R. Lourenzutti, R. A. Krohling, and M. Z. Reformat, "Choquet based TOPSIS and TODIM for dynamic and heterogeneous decision making with criteria interaction," Information Sciences, vol. 408, pp. 41-69, 2017.

[2] S. P. Wan and Y. J. Zhu, "Triangular intuitionistic fuzzy triple Bonferroni harmonic mean operators and application to multiattribute group decision making," Iranian Journal of Fuzzy Systems, vol. 13, no. 5, pp. 117-145, 177, 2016.

[3] H.-Y. Zhang, H.-G. Peng, J. Wang, and J.-Q. Wang, "An extended outranking approach for multi-criteria decision-making problems with linguistic intuitionistic fuzzy numbers," Applied Soft Computing, vol. 59, pp. 462-474, 2017.

[4] B. Roy, "Classement et choix en présence de points de vue multiples," Revue Française d'Informatique et de Recherche Opérationnelle, vol. 2, no. 8, pp. 57-75, 1968. 
[5] G. A. Gorry and M. S. Scott Morton, "A framework for management information systems," Sloan Management Review, vol. 13, pp. 56-70, 1971.

[6] A. Charnes, W. W. Cooper, and E. Rhodes, "Measuring the efficiency of decision making units," European Journal of Operational Research, vol. 2, no. 6, pp. 429-444, 1978.

[7] T. L. Saaty, The Analytic Hierarchy Process, McGraw-Hill, New Haven, CT, USA, 1980.

[8] C. L. Hwang and K. Yoon, Multiple Attribute Decision Making: Methods and Applications, pringer-Verlag, New York, NY, USA, 1981.

[9] T. H. Willis, F. Pohlkamp, and C. R. Huston, "Evaluation measures of just-in-time supplier performance," Production and Inventory Management Journal, vol. 34, no. 2, pp. 1-6, 1993.

[10] S. Opricovic, Multicriteria Optimization of Civil Engineering Systems, Faculty of Civil Engineering, Belgrade, Serbia, 1998.

[11] T. L. Saaty, The Analytic Network Process: Decision Making with Dependence And Feedback, RWS Publications, Pittsburgh, Pennsylvania, 1996.

[12] W. K. Brauers and E. K. Zavadskas, "The MOORA method and its application to privatization in a transition economy," Control and Cybernetics, vol. 35, no. 2, pp. 445-469, 2006.

[13] K. Maniya and M. G. Bhatt, "A selection of material using a novel type decision-making method: preference selection index method," Materials and Corrosion, vol. 31, no. 4, pp. 1785-1789, 2010.

[14] E. Wang, N. Alp, J. Shi, C. Wang, X. Zhang, and H. Chen, "Multicriteria building energy performance benchmarking through variable clustering based compromise TOPSIS with objective entropy weighting," Energy, vol. 125, pp. 197-210, 2017.

[15] M. Behzadian, S. K. Otaghsara, M. Yazdani, and J. Ignatius, "A state-of the-art survey of TOPSIS applications," Expert Systems with Applications, vol. 39, no. 17, pp. 13051-13069, 2012.

[16] D. Stanujkic, N. Magdalinovic, S. Stojanovic, and R. Jovanovic, "Extension of ratio system part of MOORA method for solving decision-making problems with interval data," Informatica, vol. 23, no. 1, pp. 141-154, 2012.

[17] D. Stanujkic, "An extension of the moora method for solving fuzzy decision making problems," Technological and Economic Development of Economy, vol. 19, pp. S228-S255, 2013.

[18] C. Kahraman, B. Öztayşi, and S. Çevik Onar, "A Comprehensive Literature Review of 50 Years of Fuzzy Set Theory," International Journal of Computational Intelligence Systems, vol. 9, no. sup1, pp. 3-24, 2016.

[19] K. D. Atalay and G. F. Can, "A new hybrid intuitionistic approach for new product selection," Soft Computing, pp. 1-8, 2017.

[20] M. Marttunen, J. Lienert, and V. Belton, "Structuring problems for multi-criteria decision analysis in practice: a literature review of method combinations," European Journal of Operational Research, vol. 263, no. 1, pp. 1-17, 2017.

[21] M. Aggarwal, "Compensative weighted averaging aggregation operators," Applied Soft Computing, vol. 28, pp. 368-378, 2015.

[22] K. T. Atanassov, "Intuitionistic fuzzy sets," Fuzzy Sets and Systems, vol. 20, no. 1, pp. 87-96, 1986.

[23] L. A. Zadeh, "Fuzzy sets," Information and Control, vol. 8, no. 3, pp. 338-353, 1965.

[24] S. Kumar and S. S. Gangwar, "Intuitionistic Fuzzy Time Series: An Approach for Handling Nondeterminism in Time Series Forecasting," IEEE Transactions on Fuzzy Systems, vol. 24, no. 6, pp. 1270-1281, 2016.
[25] G. Büyüközkan and F. Göçer, "Application of a new combined intuitionistic fuzzy MCDM approach based on axiomatic design methodology for the supplier selection problem," Applied Soft Computing, vol. 52, pp. 1222-1238, 2017.

[26] Z. Xu, Intuitionistic Preference Modeling and Interactive Decision Making, Springer, Berlin, Germany, 2014.

[27] W.-L. Hung and J.-W. Wu, "Correlation of intuitionistic fuzzy sets by centroid method," Information Sciences, vol. 144, no. 1-4, pp. 219-225, 2002.

[28] R. Ureña, F. Chiclana, H. Fujita, and E. Herrera-Viedma, "Confidence-consistency driven group decision making approach with incomplete reciprocal intuitionistic preference relations," Knowledge-Based Systems, vol. 89, pp. 86-96, 2015.

[29] R. R. Yager, "Pythagorean membership grades in multicriteria decision making," IEEE Transactions on Fuzzy Systems, vol. 22, no. 4, pp. 958-965, 2014.

[30] X. Peng, H. Yuan, and Y. Yang, "Pythagorean Fuzzy Information Measures and Their Applications," International Journal of Intelligent Systems, vol. 32, no. 10, pp. 991-1029, 2017.

[31] X. Zhang, "Multicriteria Pythagorean fuzzy decision analysis: a hierarchical QUALIFLEX approach with the closeness indexbased ranking methods," Information Sciences, 2016.

[32] X. L. Zhang and Z. S. Xu, "Extension of TOPSIS to multiple criteria decision making with pythagorean fuzzy sets," International Journal of Intelligent Systems, vol. 29, no. 12, pp. 1061-1078, 2014.

[33] R. R. Yager, "Pythagorean fuzzy subsets," in Proceedings of the 9th Joint World Congress on Fuzzy Systems and NAFIPS Annual Meeting, IFSA/NAFIPS 2013, pp. 57-61, Edmonton, Canada, June 2013.

[34] P. Ren, Z. Xu, and X. Gou, "Pythagorean fuzzy TODIM approach to multi-criteria decision making," Applied Soft Computing, vol. 42, pp. 246-259, 2015.

[35] Z. Zhang, C. Wang, and X. Tian, "A decision support model for group decision making with hesitant fuzzy preference relations," Knowledge-Based Systems, vol. 86, pp. 77-101, 2015.

[36] W. Wang and X. Liu, "The multi-attribute decision making method based on interval-valued intuitionistic fuzzy Einstein hybrid weighted geometric operator," Computers \& Mathematics with Applications, vol. 66, pp. 1845-1856, 2013.

[37] F. Meng, X. Chen, and Q. Zhang, "Multi-attribute decision analysis under a linguistic hesitant fuzzy environment," Information Sciences, vol. 267, pp. 287-305, 2014. 


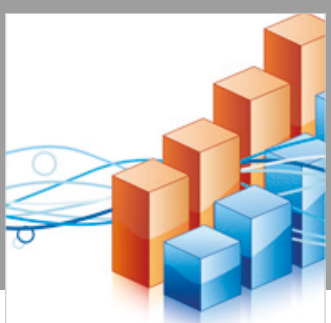

Advances in

Operations Research

\section{-n-m}
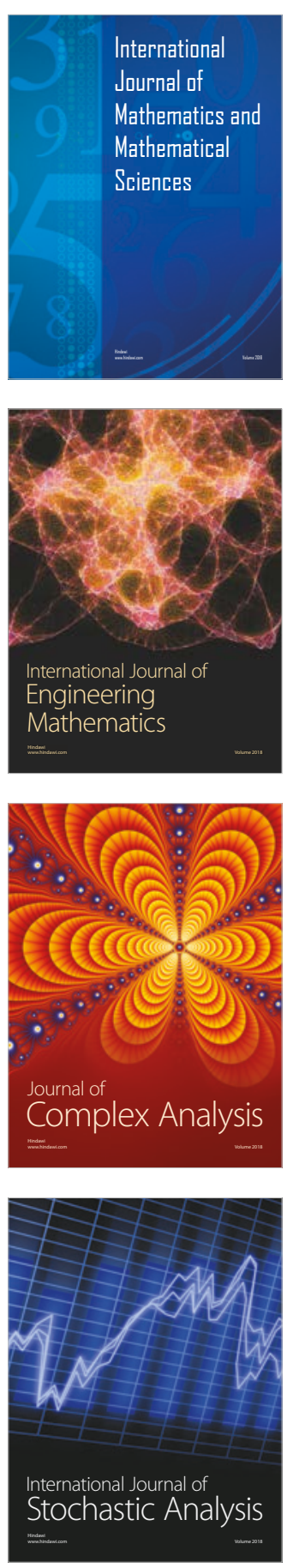
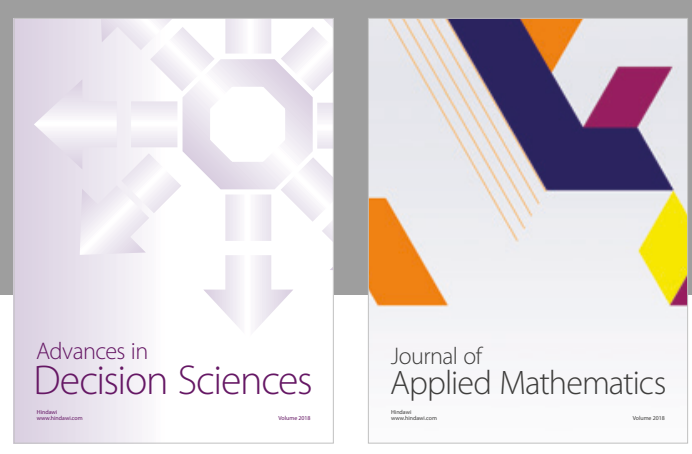

Journal of

Applied Mathematics
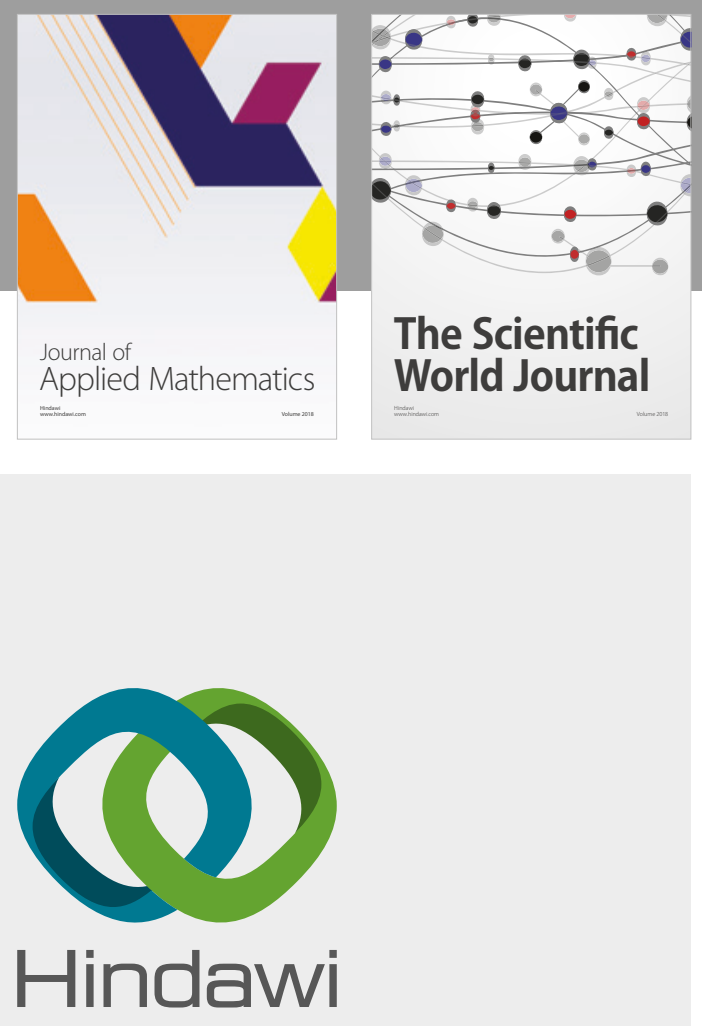

Submit your manuscripts at

www.hindawi.com

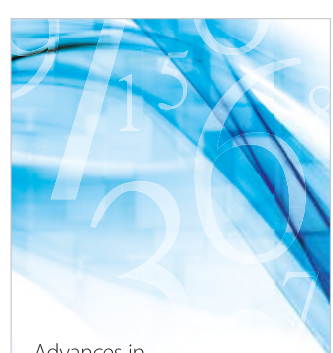

Advances in
Numerical Analysis
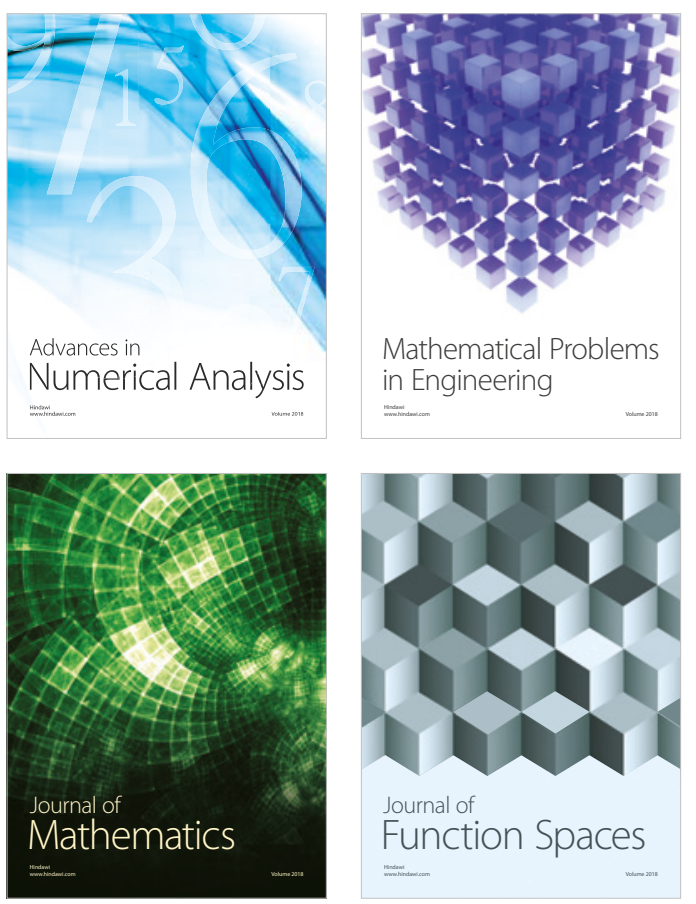

Mathematical Problems in Engineering

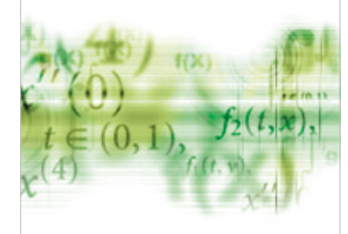

International Journal of

Differential Equations

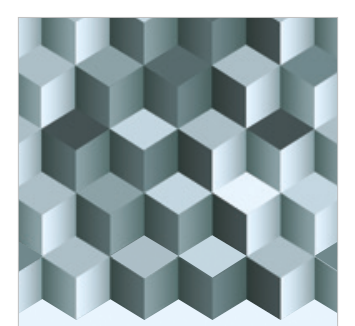

Journal of

Function Spaces
The Scientific

World Journal

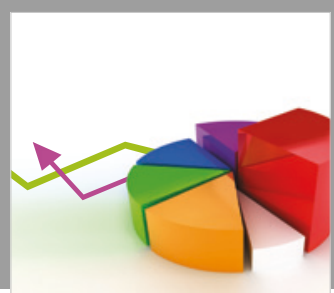

Journal of

Probability and Statistics
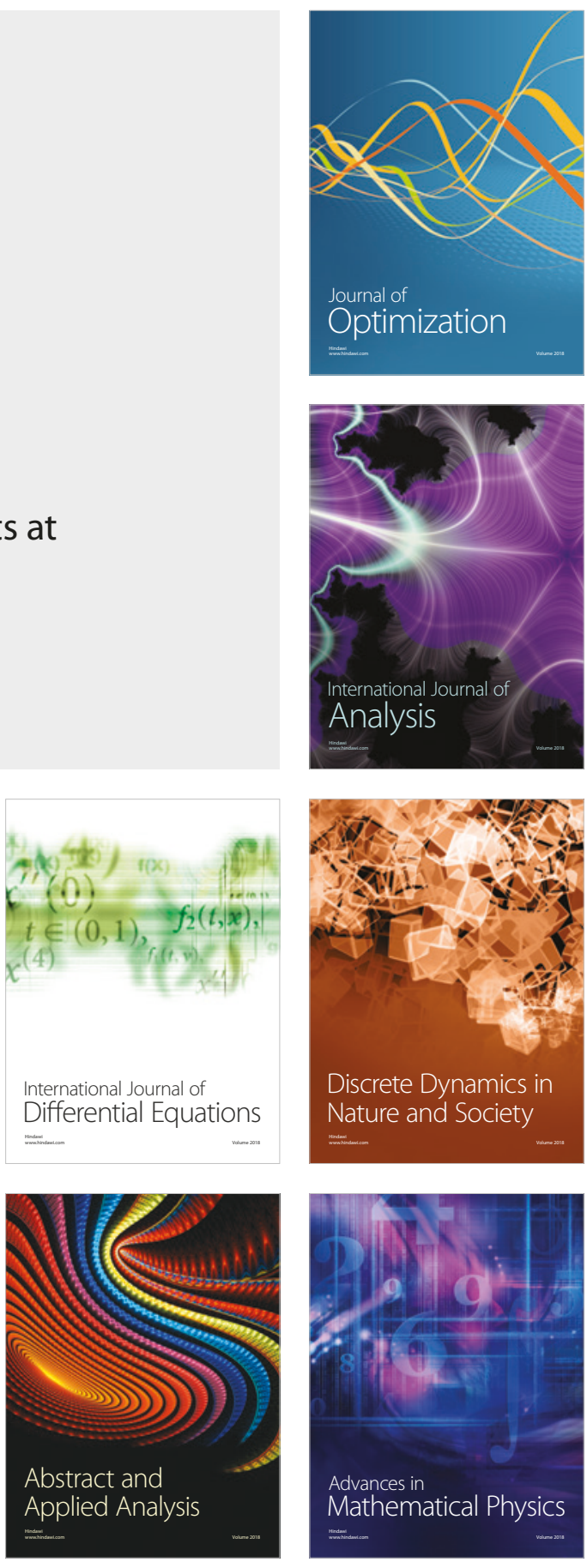